\title{
TECHNIQUE WITHOUT MYSTIQUE: A STUDY OF AUTHORITARIANISM IN ENGINEERING STUDENTS ${ }^{1}$
}

\author{
ROBERT ATHANASIOU \\ The University of Michigan
}

THE concept of authoritarianism is a well researched one in the field of social psychology and need not be treated in depth here. Kirscht and Dillehay (1967) have, for example, provided an extensive review of recent studies of authoritarianism. It is sufficient to mention that the characteristics most frequently associated with the syndrome are intolerance of ambiguity, categorical thinking, responsiveness to the demands of authority, and anti-intraception. Correlates to the syndrome include an extensive variety and large quantity of social psychological variables including extrinsic religiosity, prejudice, political-economic conservatism, and education.

The education of engineering students, as currently constituted in many colleges and universities, seems both in structure and content to favor authoritarian modes of thinking and behavior. For example, the curriculum is often thoroughly programmed and highly structured; the time allocated for courses in the humanities is severely limited; the course material in engineering is nonambiguous in the sense that nearly every problem has a single correct answer discoverable through the application of appropriate formulae; the subject matter and often the instruction are highly impersonal and nonsubjective. Additionally, because of the highly structured en-

1 This study was funded in part by the National Science Foundation under Contract No. G. S. 1382. The author received support as a Research Fellow from the National Institute of Mental Health. The author wishes to acknowledge the assistance of Dr. Stuart Kanter in collecting the data for this study. 
vironment and the amount of time the student must devote to the study of difficult material, there is little time in the engineering student's schedule for involvement with people or ideas.

Problem. It seems reasonable to predict, therefore, that the orientation of an authoritarian individual should mesh rather well with the requirements of engineering training. A number of studies have shown general support for this observation (cf., e.g., Kanter, 1967). This study is concerned with the differences between those students who have found engineering to be a satisfying major and those who have not found it so and have subsequently transferred to other fields. In particular, it is hypothesized that transfers, as a group, will show lower authoritarianism scores than satisfied engineering students, that they will show higher verbal and mathematical ability, and that as a group they will show lower acquiescence response set than engineers.

Methodology. The $f$ scale (the lower case $f$ is used to distinguish this scale from the California $F$ scale) was administered to an all male sample of 347 engineering students and 111 students who, by their sophomore year, had transferred out of engineering. These students were part of a longitudinal study begun prior to their entry as freshmen. Some of the data presented in this paper were gathered on the subjects at that time (1965).

At the time of the $f$ scale administration (1967), 98 per cent of the subjects were between the ages of 19 and 21 . The modal residential area of their families was suburban (29 per cent) with an additional eight per cent from farm families and an additional 17 per cent from large metropolitan areas. Seventy-one per cent of the sample had fathers whose occupational category could be rated middle class or higher (i.e., administrative personnel, minor professionals, and up). The fathers showed a high degree of education with 65 per cent having had some college work or even post-graduate training. In the entire sample, 26 per cent of the students' fathers had completed college and an additional 18 per cent had advanced degrees.

Protestants comprised 63 per cent of the sample, Catholics, 20 per cent, Jews, eight per cent, and Atheists or Agnostics nine percent. As might be expected, a large proportion ( 54 per cent) of the sample were first-born children.

The $f$ scale represents a selection of 14 stereopathic $(S)$ and 14 
nonstereopathic $(N)$ Likert type six-point items from a larger set ${ }^{2}$ of $F$-type and reversed $F$-type items, respectively. Selection was accomplished by item analysis against two internal criteria using a sample of Peace Corps Volunteers (Ezekiel and Athanasiou, in preparation; see also Smith, 1965). The items which correlated positively with the total score and negatively with an indicator of agreement set were chosen for the final scale. From this latter group those items were omitted which were clearly concerned with religion or politics.

The correlation between the score on the reversed $F$-type $(N)$ items and the $F$-type $(S)$ items in this scale has ranged from -.18 (see below) to -.62 in various samples and has always been negative.

A test-retest study using a sample of 8 male and 11 female students has yielded a coefficient of stability of .86 over a two-week period.

Results. The individual items of the $f$ scale were analyzed in a simple double cross-validation paradigm (McCormick, 1959) using the method of compound probabilities (Baker, 1952); the external criterion was whether or not the subject had transferred out of engineering. Tables 1 and 2 show those items which discriminated between the two groups.

The few items which did not survive the validation procedure at adequate statistical levels are shown in Table 3 . Since these items were small in number, they were left in when the means and standard deviations were calculated for the $N, S$ and $f$ scores which are presented in Table 4. The scores on the verbal and mathematics section of the Scholastic Aptitude Test (SAT) of the College Entrance Examination Board (CEEB) are also presented in Table 4. Mathematics SAT's did not differ for the two groups.

The correlation coefficient $r_{n s}$ may be interpreted as an indication of response set since it demonstrates the relationship between reversed $(N)$ and positive $(S)$ items. For engineers alone the co-

2 This unpublished set of items was developed by Christie, R., Lane, H., Sanford, N., Stern, G., and Webster, H. A copy of the items (photoprint or 35 $\mathrm{mm}$. microfilm) may be obtained by requesting document number 8332 from the ADI Auxiliary Publications project, Photoduplication Service, Library of Congress, Washington, D. C. 20025. The request must be accompanied by a check or money order in the amount of $\$ 1.25$ payable to: Chief, Photoduplication Service, Library of Congress. 
TABLE 1

Items to Which "Engineers" Indicated Greater Agreement than Did "Transfers." $(p<.01)$ These Items are all from the $S$ Subscale. Responses Ranged from $1=$ Strongly Disagree to $6=$ Strongly Agree

2. What our youth need most is strict discipline, rugged determination, and the will to work and fight for family and country.

3. The minds of today's youth are being hopelessly corrupted by the wrong kind of literature.

6. One of the best assurances for peace is for us to have the biggest bomb and not be afraid to use it.

12. Sex crimes, such as rape and attacks on children, deserve more than mere imprisonment; such criminals ought to be publicly whipped or worse.

13. Drunks and degenerates who end up in the gutter on skid row deserve their fate because of their lack of moral fibre.

14. There may be a few exceptions, but, in general, members of a racial group tend to be pretty much alike.

16. The poor will always be with us.

17. It usually helps the child in later years if he is forced to conform to his parents' ideas.

18. A sexual pervert is an insult to humanity and should be punished severely.

21. The worst danger to real Americanism during the last fifty years has come from foreign ideas and agitators.

22. A child ought to be whipped at once for any sassy remark.

24. Most homosexuals are hardly better than criminals and ought to be severely punished.

25. Army life is a good influence on most young men.

\section{TABLE 2}

Items to Which "Transfers" Indicated Greater Agreement than Did "Engineers." $(p<.01)$ These Items are from the $N$ Subscale

1. Many modern paintings have both beauty and purpose.

4. Most censorship of books or movies is a violation of free speech and should be abolished.

7. Sex offenders should be treated with expert care and understnading rather than punishment.

10. What a youth needs most is the flexibility to work and fight for what he considers right personally even though it might not be best for his family and country.

28. As young people grow up they ought to try to carry out some of their rebellious ideas and not be content to get over them and settle down.

Items to which "transfers" indicated greater agreement than did "engineers." $(p<.05)$

5. Science declines when it confines itself to the solution of immediate practical problems.

8. One of the most important things for children to learn is when to question authority.

15. Poverty can be eliminated.

19. Strict discipline of children often interferes with the development of selfdirection and personal responsibility.

20. Almost everyone has at some time hated his parents.

26. It is the duty of a citizen to criticize or censure his country whenever he considers it to be wrong. 
TABLE 3

Items Which Did not Discriminate between Engineers and Transfers

9. Human nature doesn't make war inevitable for man will some day establish a peaceful world. $(N)$

11. It is only natural and right for each person to think that his family is better than any other. $(S)$

23. It would probably be best to discourage feeble-minded people from having children. $(N)$

27. Without the friendly cooperation of many other nations, the United States probably could not survive for very long. $(N)$

TABLE 4

Descriptive Statistics for Transfer Students and for Those Remaining in Engineering

\begin{tabular}{|c|c|c|c|c|c|}
\hline Transfers & $\begin{array}{l}\text { Authori- } \\
\text { tarianism } \\
(f)^{*}\end{array}$ & $\begin{array}{c}\text { Stereopathy } \\
(S)\end{array}$ & $\begin{array}{c}\text { Non- } \\
\text { Stereopathy } \\
(N)\end{array}$ & $\begin{array}{l}\text { Verbal } \\
\text { SAT }\end{array}$ & $\begin{array}{l}\text { Mathematical } \\
\text { SAT }\end{array}$ \\
\hline Mean & 49.73 & 34.23 & 56.05 & 588.55 & 667.68 \\
\hline$S D$ & 15.89 & 9.05 & 8.81 & 81.30 & 63.43 \\
\hline \multicolumn{6}{|l|}{$\begin{array}{l}N=111 \\
\text { Engineers }\end{array}$} \\
\hline Mean & 58.68 & 40.66 & 53.46 & 557.29 & 670.18 \\
\hline \multirow{3}{*}{$\begin{array}{l}S D \\
N=347 \\
\text { Difference be- } \\
\text { tween engineer \& } \\
\text { transfer means } \\
\text { significant at }\end{array}$} & 14.58 & 8.68 & 7.77 & 73.28 & 65.72 \\
\hline & & & & & \\
\hline & $p<.001$ & $p<.001$ & $p<.05$ & $p<.01$ & $N S$ \\
\hline
\end{tabular}

Note. $-f$ scores were calculated for each subject by the formula $S+70-N=f$.

efficient $r_{n s}=-.312$, and for transfers alone $r_{n s}=-.18$. A large negative coefficient would indicate lack of response bias. However, these two values of $r_{n s}$, while different from zero (at $p<.05$ ), do not differ from each other at an acceptable probability level.

The engineers and transfers differed on a number of other variables which have traditionally been associated with research on authoritarianism. The frequency distributions of responses of the two groups were partitioned and a $X^{2}$ statistic $(d f=1)$ was computed for a number of other variables. Among these was religious affiliation: transfers, their mothers, and their fathers showed a larger proportion of non-Christians than would be expected by chance $p<.001, .001, .05$, (respectively). Transfers also indicated that they attended religious services less often than engineers $(p<.02)$.

Transfers were disproportionately over-represented in the "only 
child" category in a birth order question. "Only children" comprised 17 per cent of the transfer sample and only seven per cent of the engineers $(p<.01)$.

Fathers of transfers were more likely to have been born outside of the USA. Sixteen per cent of the transfers' fathers versus seven per cent of the engineers' fathers were foreign born $(p<.05)$.

Mothers of students who transferred tended to show slightly more education than those of engineers $(p<.1)$. Twenty-eight per cent of the transfers' mothers also had a full-time job versus only $\mathbf{1 7}$ per cent of the engineers' mothers $(p<.05)$, but the mothers' occupation levels did not differ.

Over the entire population of students the $f$ scale showed a significant correlation only with Verbal SAT $(r=-.307)$. The scale did not correlate with fathers' or mothers' education nor with their occupational status. Neither did the $f$ scale scores correlate with the subjects' ages nor their position on an urban-rural continuum.

The phi coefficient relating $f$ scale position to the engineer-transfer dichotomy is $\phi=.262$. The $X^{2}$ statistic from which $\phi$ was calculated is significant beyond $p<.001$. The index of predictive association, $\lambda$, (Hays, 1963, p. 608) which shows the proportional reduction in the probability of error in prediction given the $f$ scale score, is 12.9 per cent.

Discussion. While each of the subscales ( $N$ and $S$ ) showed some ability to discriminate between engineers and transfers, the $S$ subscale did the better job. This is evident from the comparison of the sample estimates of the proportional reduction of variance in behavior (i.e., to transfer or not to transfer) given $S$ or $N$. For the $S$ subscale, the estimated $\omega^{2}$ (Hays, 1963, p. 327) is nearly nine per cent, while for the $N$ subscale, it is not quite one and one-half per cent.

The failure of the $N$ subscale to show a large negative correlation with the $S$ subscale is disappointing, especially since the items were carefully chosen in an attempt to eliminate the response set factor. The hypothesis that engineers would show a higher degree of response bias is not supported by these data. $S$ subscale scores were negatively correlated with verbal SAT for both groups. On the other hand, the $N$ subscale showed little or no correlation with VSAT. Verbal ability has frequently been cited as a factor in response set problems. 
The average item mean score on the $N$ subscale was 3.82 (the possible range was from $1=$ strongly disagree to $6=$ strongly agree) for engineers and 4.00 for transfers, indicating that both groups showed mild acceptance regarding the liberal type items. With regard to the $S$ subscale, however, the average item mean scores were 2.44 and 2.90 for transfers and engineers, respectively, indicating that both groups rejected the authoritarian items with the transfers rejecting them more emphatically than the engineers. It appears that for these populations the degree of rejection of anti-liberal statements is more discriminating than the acceptance of pro-liberal statements.

It would be abundantly clear to the most casual observer that, on the campus where these data were collected, there is an immense difference between the Weltanschauung of the Language, Science and Arts School and that of the Engineering School. One may reasonably question whether the difference in $f$ scale scores occurs after transferring or whether it exists prior to transfer. While it is not possible to answer this question directly, there are some indications in the longitudinal data which suggest that a liberal orientation characterized the transfers prior to their entry to college. For example, on a 7-point scale administered prior to their entrance as freshmen, the transfers as compared to engineers rate themselves as more spontaneous than rigid $(p<.001)$, more politically liberal than conservative $(p<.02)$, more "open" than "closed" $(p<.02)$, and more unconventional than conventional $(p<.001)$. From these and other similar data one may infer that the brighter (as indicated by SAT scores), more liberal-oriented students tend to leave the engineering school for greener pastures. This seems consistent with data reported elsewhere (cf. Robinson, Athanasiou, and Head, 1967) regarding employee turnover in the engineering profession at large.

Similar differences between attitudinal positions of various college majors have been documented by Newcomb and Feldman (1968), and a study is currently under way to ascertain the effect of these "attitudinal atmospheres" on changes in major. It would seem appropriate to suggest that in the near future data such as these be made available for the counseling of pre-college or college students where questions arise with regard to proposed field of specialization. Attitudinal measures such as the scale presented here do not, 


\section{EDUCATIONAL AND PSYCHOLOGICAL MEASUREMENT}

in this author's opinion, have sufficient predictive validity to allow for their use as selection or placement instruments. It is even ethically questionable wheter they should be used as such if they did have the requisite level of validity.

\section{REFERENCES}

Baker, P. C. Combining Tests of Significance in Cross-Validation. Educational and Psychological Measurement, 1952, 12, 300 306.

Hays, W. L. Statistics for Psychologists. New York: Holt, Rinehart and Winston, 1963.

Kanter, S. The Social Psychology of Premature Occupational Choice: An Investigation of Student Careers in an Undergraduate Engineering School. Unpublished doctoral dissertation, University of Michigan, Ann Arbor, 1967.

Kirscht, J. and Dillehay, R. Dimensions of Authoritarianism. Lexington: University of Kentucky Press, 1967.

McCormick, R. L. An Evaluation of Two Methods of Cross-validation. Psychological Reports, 1959, 5, 127-130.

Newcomb, T. M. and Feldman, K. A. The Impacts of Colleges upon Their Students: A report to the Carnegie Foundation for the Advancement of Teaching. Ann Arbor: Institute for Social Research, 1968.

Robinson, J., Athanasiou, R., and Head, Kendra. Measures of Occupational Attitudes and Occupational Characteristics. Ann Arbor: Institute for Social Research, University of Michigan, 1967.

Smith, M. Brewster. An Analysis of Two Measures of "Authoritarianism" among Peace Corps Teachers. Journal of Personality, $1965,33,513-535$. 